\title{
Interannual variability in western US precipitation
}

\author{
B. Rajagopalan ${ }^{\mathrm{a}}$, U. Lall ${ }^{\mathrm{b}, *}$ \\ ${ }^{a}$ Lamont-Doherty Earth Observatory, Columbia University, Palisades, NY, USA \\ ${ }^{\mathrm{b}}$ Utah Water Research Laboratory, Utah State University, Logan, UT, USA
}

Received 27 January 1998; accepted 30 May 1998

\begin{abstract}
Low-frequency (interannual or longer period) climatic variability is of interest, because of its significance for the understanding and prediction of protracted climatic anomalies. Since precipitation is one of the key variables driving various hydrologic processes, it is useful to examine precipitation records to better understand long-term climate dynamics. Here, we use the multi-taper method of spectral analysis to analyze the monthly precipitation time series (both occurrence and amount) at a few stations along a meridional transect from Priest River, ID to Tucson, AZ. We also examine spectral coherence between monthly precipitation and widely used atmospheric indices, such as the central Northern Pacific (CNP) and southern oscillation index (SOI). This analysis reveals statistically significant 'signals' in the time series in the 5-7 and 2-3 year bands. These interannual signals are consistent with those related to El-Niño southern oscillation (ENSO) and quasi-biennial variability identified by others. (c) 1998 Elsevier Science B.V. All rights reserved.
\end{abstract}

Keywords: Precipitation; El Niño Southern oscillation; Low frequency climate variability

\section{Introduction}

The identification and explanation of recurrent climatic patterns can have significant implications for long-term climatic forecasts. Though the variation in climate from year to year may seem random, a careful examination of historical data can sometimes reveal a remarkably coherent global pattern of oceanic and atmospheric anomalies, which reappears every few years in approximately the same sequence and form. There is growing evidence to this effect and also to the fact that global and regional climate variability is well organized on interannual and interdecadal time scales (Mann and Park, 1993; Mann and Park, 1994). Two modes of low-frequency variability (at the interannual

\footnotetext{
* Corresponding author. E-mail: rbala@rosie.ldgo.columbia.edu or ulall@cc.usu.edu
}

time scales) are the El Niño/southern oscillation (ENSO) and the quasi-biennial oscillation (QBO) (Rasmusson and Carpenter, 1983; Ropelewski and Halpert, 1986; Burroughs, 1992; Peixoto and Oort, 1992). ENSO-related events can have major impacts on US atmospheric weather patterns, which, in turn, modulate the surface climate (i.e. wind, temperature and precipitation) and, consequently, streamflow (Cayan and Peterson, 1989; Cayan and Webb, 1992; Kahya and Dracup, 1993; Kahya and Dracup, 1994).

Recognition of low-frequency variability leads to changes in the interpretation and utility of hydro-climatic records. The impact of climate variability on the hydrologic cycle is also important from the point of view of understanding the underlying dynamics of the system. The identification of coherent, low-frequency patterns, may also be relevant to interpretation of long-range persistence or the Hurst effect. 
From the recent works of Klein and Bloom (1987), Kiladis and Diaz (1989), Cayan and Peterson (1989), Leathers et al. (1991), Lins (1993) and Mann et al. (1995), among numerous others, it is clear that atmospheric and oceanic conditions in the Pacific basin exert considerable influence on the lowfrequency patterns of North American climatic and hydrologic variability.

In this study, we focus on connections between two atmospheric circulation indices and variability in precipitation along a meridional transect in the western US. Past studies include simply examining the historical records for subtle changes in climatic patterns (Rasmusson and Carpenter, 1983; Rasmusson and Wallace, 1993), and using the correlation type of analysis to find strong statistical relationship between atmospheric indices versus precipitation, temperature and streamflow (Yarnal and Diaz, 1986; Bradley et al., 1987; Cayan and Peterson, 1989; Redmond and Koch, 1991), and a harmonic analysis to examine the climate anomalies (Ropelewski and Halpert, 1986; Ropelewski and Halpert, 1987; Ropelewski and Halpert, 1989; Piechota and Dracup, 1994), on a case by case basis.

In this paper, we use the nonparametric multi-taper method of spectral analysis of Thomson (1982), on the time series of monthly precipitation and monthly rates (defined as number of wet days in the month divided by the number of days in the month), a relatively direct measure of the occurrence process.

A brief description of the data sets is first provided. The multi-taper method of spectral analysis is next outlined. Results from the analysis are then summarized and discussed.

\section{Data sets}

We chose seven stations at approximately $112^{\circ}-$ $116^{\circ} \mathrm{W}$ longitude going from Idaho (ID) to Arizona (AZ). The station and data information (latitude, longitude, elevation, length of record and source of data) are given in Table 1. From the daily precipitation data, total monthly precipitation and the monthly rate were first calculated for each station. In order to look for connections in precipitation with large-scale atmospheric fluctuation (ENSO, QBO), we chose two atmospheric indices, namely, the southern oscillation index (SOI) and the central North Pacific (CNP), which have been shown to be good indicators for western US atmospheric variability (Cayan and Peterson, 1989). The hydrologic impact of variability in atmospheric circulation is strong in this arid region.

The SOI data is a time series of monthly mean difference in sea level pressure (SLP) at Tahiti (approximately $150^{\circ} \mathrm{W}, 18^{\circ} \mathrm{S}$ ) and Darwin (approximately $130^{\circ} \mathrm{E}, 13^{\circ} \mathrm{S}$ ), and is a commonly used indicator of ENSO. ENSO is an identified coupled ocean-atmosphere phenomena in the tropical Pacific ocean, with significant impacts on global climate. On average, the western Pacific is warm with a low pressure over Indonesia and northern Australia, while the eastern Pacific is cold, with a high pressure centered near Tahiti. This east-west temperature and pressure

Table 1

Data sets analyzed

\begin{tabular}{lrr}
\hline & Latitude & Longitude \\
\hline Priest River, Idaho (PRR) & $48^{\circ} 21^{\prime} \mathrm{N}$ & $116^{\circ} 50^{\prime} \mathrm{W}$ \\
Sandpoint, Idaho (SNP) & $48^{\circ} 17^{\prime} \mathrm{N}$ & $116^{\circ} 34^{\prime} \mathrm{W}$ \\
Logan, Utah (LOG) & $41^{\circ} 45^{\prime} \mathrm{N}$ & 2380 \\
Snake Creek, Utah (SNC) & $40^{\circ} 33^{\prime} \mathrm{N}$ & 2100 \\
Alton, Utah (ALT) & $37^{\circ} 26^{\prime} \mathrm{N}$ & $111^{\circ} 48^{\prime} \mathrm{W}$ \\
Miami, Arizona (MIM) & $33^{\circ} 24^{\prime} \mathrm{N}$ & $112^{\circ} 29^{\prime} \mathrm{W}$ \\
Tucson, Arizona (TUS) & $32^{\circ} 15^{\prime} \mathrm{N}$ & $110^{\circ} 53^{\prime} \mathrm{W}$ \\
Southern Oscillation Index (SOI) & SLP (Tahiti)-SLP (Darwin) & $110^{\circ} 57^{\prime} \mathrm{W}$ \\
Central Northern Pacific (CNP) & Average SLP (170E-150W, 35N-55N) & 3560 \\
\hline
\end{tabular}

SLP = sea level pressure.

All the data except SOI and CNP were obtained from Earth Info CD-ROM.

SOI and CNP data were obtained from Dr Dan Cayan.

All the data sets were of the same length, i.e. 1932-1992. 
gradient results in strong trade winds blowing from the eastern Pacific to western Pacific (this is also known as the Walker circulation) and, consequently, strong convection and very high precipitation around the western Pacific relative to the east. During El Niño years, a warm anomaly appears off of South America, which reduces the temperature gradient and hence the winds. The weakened winds help in increasing the sea surface temperatures and get further weakened, thus, setting up a positive feedback. The weakened trade winds also reduce the pressure gradient (Cane, 1986; Philander, 1990). This introduces a major perturbation of the global atmosphere and has far-reaching effects on global climate (Ropelewski and Halpert, 1987). The ENSO, generally referred to as El Niño, has, typically, a life cycle of approximately 22 months and recurrence interval of approximately 3-8 years. The weakening of the trade winds and subsequently the pressure gradient, shows up as a low negative value in SOI - which means an El Niño event is in progress.

ENSO has teleconnections to higher latitudes through wave-like patterns that change the jet stream and storm track locations in the northern Pacific, which, in turn, have a profound impact on regional temperatures and precipitation in the US (Horel and Wallace, 1981). The CNP index (Cayan and Peterson, 1989) constructed by averaging the sea level pressure (SLP) over the region $35^{\circ} \mathrm{N}-55^{\circ} \mathrm{N}$ and $170^{\circ} \mathrm{E}-150^{\circ} \mathrm{W}$, serves as a good measure to reflect the ENSO teleconnection in the northern Pacific. This index is similar to the Pacific North America (PNA) index, and is available for a longer period than PNA. The CNP index has been shown to be more strongly tied to the precipitation in the north western US than SOI (Cayan and Webb, 1992).

The SOI and CNP data were obtained from Dr D.R. Cayan at the Scripps Institution of Oceanography, San Diego.

\section{Methods}

Spectral analysis (Jenkins and Watts, 1968; Brillinger, 1981; Percival and Walden, 1993) is a useful tool for exploring structured temporal variations embedded in hydroclimatic data. The basic idea (Eq. (1)) is to decompose the time series into orthogonal, harmonic components using Fourier basis functions:

$$
\begin{aligned}
x(t) & =\mu+\sum_{j=1}^{N / 2}\left\{A_{j} \cos \left(2 \pi f_{j} t\right)+B_{j} \sin \left(2 \pi f_{j} t\right)\right\} \\
t & =0, \ldots, N-1,
\end{aligned}
$$

where $x(t)$ is the observed time series of length $N, \mu$ is the mean of the series, and $A_{j}$ and $B_{j}$ are amplitude coefficients of cosine and sine terms at frequencies $f_{j}$ (defined as $j / N ; 1 \leq j \leq N$ ), respectively.

By construction, the information in each component at different frequencies is independent (i.e. $A_{j}$ and $B_{j}$ are uncorrelated for different values of $j$ ), thus allowing the annual cycle and other cyclic phenomena to be isolated. If there are no significant periodicities in the data set, the $E\left[A_{j}\right]=E\left[B_{j}\right]=0$, and $E\left[A_{j}^{2}\right]=E\left[B_{j}^{2}\right]=\sigma_{j}^{2}$, the variance associated with the $j$ th component. The variance, $\sigma^{2}$, of the time series, $x(t)$, is then simply the sum of the variances of these components. The power spectrum $S(f)$ is then defined as the variance associated with the harmonic component with a frequency $f$. Theoretically, for a white noise process (i.e. the time series is serially uncorrelated and Gaussian), all frequency components contribute equally to the process, and the spectrum is a constant horizontal line. If the time series is strictly periodic with a frequency $f^{*}$, all the variance is associated with a frequency component at that frequency, and the theoretical spectrum is represented by a vertical line at $f^{*}$ of height equal to the series variance. For multiple periodic components, theoretically, the spectrum will have vertical lines of height equal to the squared amplitude of the respective periodic components. A linear or higher-order trend in the series, leads to a corresponding variance contribution at the zero frequency (i.e. a harmonic with an infinite period). An autoregressive (AR) process of order 1 is often used as a null model to account for serial correlation. The theoretical spectrum for such a process is a monotonically decreasing function of frequency given as (Bartlett, 1966):

$$
S(f) \frac{\sigma^{2}}{1-2 \rho \cos \left(\pi f / f_{N}\right)+\rho^{2}}
$$

The spectrum of a long memory or a fractal process can be log linear with frequency. A time series with periodic, trend and autoregressive components, will have a spectrum that shows a combination of these 
features. The spectrum $S(f)$ has a dual relationship to the autocovariance function $s(\tau)$ of the time series, as indicated in Eq. (3):

$S(f)=\int_{-\infty}^{\infty} s(\tau) e^{-i 2 \pi f t} \mathrm{~d} t$ and $s(\tau)=\int_{-\infty}^{\infty} S(f) e^{i 2 \pi f t} \mathrm{~d} f$.

The spectrum and the autocovariance function are different, but complement representations of the serial dependence information in a time series. The spectrum identifies this information with distinct frequencies, while the autocovariance represents it in terms of discrete lags. The dependence structure for each frequency component in time is essentially aggregated together in terms of lags in the autocovariance function. A strictly periodic time series will have a periodic autocovariance function, that can be modeled by a high-order autoregressive model. This is represented as a single component in the spectrum. The spectrum is thus useful for decomposing the serial dependence information into periodic (or nearly so), autoregressive and trend components. In practice, many methods, parametric and nonparametric, have been developed to estimate the spectrum from data. The reader is referred to Percival and Walden (1993) and Thomson $(1982 ; 1990)$ for a detailed discussion of the attributes of these methods. Since we use the spectrum as a data exploratory tool, nonparametric methods are appropriate.

Nonparametric methods for spectral analysis estimate the spectrum directly from the data, using either a discrete Fourier transform of the data (i.e. the periodogram) or, equivalently, of the sample autocovariance function. Neither of these is usually satisfactory for related reasons. Depending on how it is computed [i.e. with the divisor of $N$ or $(N-\tau)$ for lag $\tau$ ], the bias and/or variance of the sample estimate of the autocovariance can increase with lag. Since the estimate of the spectrum at any frequency will depend on the autocovariance function at each lag, this impacts the spectrum at every frequency. The spectrum computed using a direct Fourier transform of the data, is biased in the manner shown below. The finite discrete Fourier transform (DFT) of the data, $x(0), \ldots, x(t), \ldots, x(n-1)$ is given by:

$y(f)=\sum_{t=0}^{n-1} e^{-i 2 \pi f[t-(n-1) / 2]} x(t)$.
For a finite data set, the DFT is related to the spectrum as:

$y(f)=\int_{-1 / 2}^{1 / 2} \frac{\sin N \pi(f-v)}{\sin \pi(f-v)} \mathrm{d} Z(v)=\int_{-1 / 2}^{1 / 2} G(N, f, v) \mathrm{d} Z(v)$,

where the spectrum $S(f)$ is defined through $\{S(f) \mathrm{d} f=E$ $\left.\left[|\mathrm{d} Z(f)|^{2}\right]\right\}$, where $E[$.$] denotes expectation.$

The periodogram estimate $S_{\mathrm{p}}(f)$ is simply $|y(f)|^{2}$, whose properties will not correspond to those of $S(f)$, since the term $G(N, f, v)$ in Eq. (5) poorly approximates a Dirac delta function. This term is a consequence of a rectangular window of width $N$ (the length of record) placed on the underlying process. The consequence of convoluting a rectangular data window with the Fourier transform is 'leakage' of power from frequencies with high power to a broad band of frequencies, in a manner that depends on the sample size $N$. The practical implication of this problem is that the resulting spectral estimate appears to be broad band and the peaks do not meet tests for statistical significance, i.e. structure in the series is not identified. The traditional solution to this problem is to apply a taper window to the data (or equivalently to the autocovariance function) to downweight the data near the ends (or the autocovariance estimates at long lags). Typically, the data on both ends of the time series are smoothly downweighted using a prescribed function. Given that the number of frequencies considered and hence, the number of parameters to be estimated increases with $N$, each periodogram ordinate (i.e. estimate of the spectrum at each frequency $f_{j}$ ) has only 2 degrees of freedom (dof), irrespective of the length of the time series. Tapering further increases the variance of the estimate, since it can be viewed as a reduction of the effective sample size. Given the highly-associated variability, the periodogram cannot be reliably used to assess frequency structure. The traditional solution to this problem is to smooth the periodogram using a variety of weighted moving average smoothers applied across frequencies. While these reduce the variance of the spectral estimates, sharp peaks can be smeared over the averaging window, making the detection of harmonics difficult.

Thomson (1982) provides the following motivation for the multi-taper algorithm for spectrum estimation. 
He points out that: (a) the classical periodogram is an inconsistent estimator of the spectrum; (b) without a taper window, it may be too biased to be useful; (c) usual tapers can increase variance of estimation by reducing the effective sample size; (d) smoothing the periodogram is unsatisfactory for spectra with a large range and line and broadband components, since the true spectrum is not smooth; and (e) since the periodogram-based spectral estimator does not directly use phase information, line detection is poor. He sets his sights on developing an estimator that: (a) is consistent; (b) has good small sample performance in terms of estimation variance; (c) is data adaptive; (d) is nonparametric, i.e. locally approximates the spectrum using information only from neighboring frequencies; (e) works well with spectra with a high dynamic range; (f) is computationally easy; and $(\mathrm{g})$ whose statistics can be estimated, and hence significance tests for line components and coherence can be provided. We outline the aspects of the multi-taper algorithm relevant to our presentation and refer the reader to Thomson (1982) and chap. 7 of Percival and Walden (1993) for details. Percival and Walden (1993) include a detailed example application to the monthly flows of the Willamette River in Oregon.

The multi-taper method, as its name implies, uses $K$ different data tapers (or downweighting schemes). The tapers are specially designed so that they lead to independent (orthogonal) estimates of the spectra, weight different segments of the data quite differently, and hence, emphasize different features of the spectrum. The $K$ spectra computed using each of the tapers are then combined to form the final spectrum estimate in a manner that provides substantial gains in bias and variance, and hence, in signal detection.

Given the estimate $y(f)$, one can seek a solution for $\mathrm{d} Z\left(f_{\mathrm{o}}\right)$ in Eq. (5) in some locale $\left(f_{o}-W, f_{\mathrm{o}}+W\right)$ of a frequency $f_{\mathrm{o}}$. This is an inverse problem parameterized by $G(N, f, v)$. Thomson pursues a least squares solution, by considering a weighted eigenfunction expansion in this locale, and then an appropriate combination of the resulting estimates. Consider the $K$ term $(k=0, \ldots, K-1)$ eigenfunction expansion:

$\lambda k(N, W) \cdot U_{k}(N, W ; f)=\int_{-W}^{W} G(N, f, v) U(N, W ; v) d v$, where $U_{k}(N, W ; f)$ is the $k^{\text {th }}$ eigenfunction centered at $f$, with window width $W$, and $\lambda_{k}(N, W)$ the corresponding eigenvalue.

The eigenfunctions (called discrete prolate spheroidal wave functions) are ordered by decreasing eigenvalue, with the first $N W$ eigenvalues close to 1 . Consequently, of all functions that are DFTs of some discrete sequence, these leading eigenfunctions have a maximum energy concentration in the interval $\left(f_{\mathrm{o}}-\right.$ $\left.W, f_{\mathrm{o}}+W\right)$. This implies that the tapers are leakage resistant. The window width $W$ is $0<1 / 2$, and is usually of the order of $1 / N$ to retain high resolution of the resulting estimate. The idea here is that if the $K$ term approximation in Eq. (6) is 'good', then a good solution to the estimation of $S(f)$ is available. Thomson derives such a solution by first considering $K$ spectral estimates corresponding to each of the eigenfunctions, and then combining them using an optimality criteria derived from estimates of the mean square error of estimate of the spectrum in the locale of interest. The $K$ eigen spectra $S_{k}(f), k=0, \ldots, K-1$, are defined through:

$y(f)=\sum_{t=0}^{n-1} x(t) \frac{v_{t, k}(N, W)}{\epsilon_{k}} e^{-i 2 \pi f(t-(N-1) / 2)}$,

$S_{k}(f)=\left|y_{k}(f)\right|^{2}$,

where $\epsilon_{k}$ is 1 for $k$ even, and $i$ for $k$ odd; and $v_{t, k}(N$, $W$ ), the $k^{\text {th }}$ discrete prolate spheroidal sequence (DPSS), is defined such that its Fourier transform gives $U_{k}\left(N, W ; f-f_{\mathrm{o}}\right)$.

The multi-taper spectral estimate is obtained as:

$S_{M}(f)=\sum_{k=0}^{K-1} w_{k}(f) S_{k}(f)$,

and $w_{k}(f)$ is a weight associated with the $k^{\text {th }}$ eigen spectrum estimate at frequency $f$.

The windows $U_{k}($.$) are positive everywhere, and$ hence, the problem of getting negative estimates of $S(f)$ resulting from traditional higher-order spectral windows is averted. The combined estimate from $K$ orthogonal tapers also circumvents the loss of resolution and variance increase problems, endemic to periodograms smoothed with a single taper. The orthogonality of the eigenfunctions leads the $S_{k}$ to be approximately uncorrelated. The multi-taper method recovers information lost by using a single taper and by ignoring the phase information in the 
periodogram. A number of strategies for choosing the weights $w_{k}(f)$ at each frequency $f$, are indicated by Thomson (1982). These range from a simple average, to weights proportional to the eigenvalues $\lambda_{k}$, to a fully data adaptive and recursive procedure that internally estimates the bias and variance of the local estimate. We used the last two strategies in our work. The latter allows improved separation of the line and broad band spectral components. We refer the reader to Thomson (1982) for details of the DPSS and the $w_{k}$, and discuss the choice of $W$ and $K$, the user-selected parameters of the model.

The half bandwidth $W$ is usually specified in terms of the Rayleigh frequency $f_{\mathrm{R}}=(n \Delta t)^{-1}$, where $\Delta t$ is the sampling frequency, as $p f_{\mathrm{R}}$, where $p$ is usually a small integer. The corresponding DPSS is called a $p \pi$ taper. The corresponding spectral estimate averages in the frequency band $f \pm p f_{\mathrm{R}}$. For example, a $2 \pi$ taper, for a 60 year data set, would average over $f \pm$ 0.03333 cycles per year. Note that this would correspond to periods of 2.3-2.7 years for a band centered at $f=0.4$, and 5-7.5 years for a band centered at $f=$ 0.1667 , and that everything with a period greater than 33 years (1/0.03333) will be lumped with the 'trend'. We see from this example that it is desirable to use a small value of $p$ to obtain a higher resolution in the low-frequency range. On the other hand, a small value of $p$ can lead to peak splitting in the high-frequency range. Comparing estimates obtained by varying $p$ over a small range is consequently desirable. As $K$ increases, the variance of $S_{\mathrm{M}}$ decreases, however, the broad band bias can increase. $S_{\mathrm{M}}$ is distributed as $\chi^{2} 2 K$, rather than as $\chi^{2} 2$ for the periodogram, and the increased dof corresponds to the reduced variance. The first $(2 p-1)$ tapers are leakage resistant, so $K$ is usually taken to be $2 p-1$. As $p$ increases, the number of leakage-resistant tapers increases. Note that, as $N$ increases, one can increase $p$ while retaining the same spectral resolution. The estimate $S_{\mathrm{M}}(f)$ is unbiased, but its local features (amplitude) will depend on $p$ and $K$. Consequently, it is desirable to also look at a significance test for line components, based on the ratio of variance explained by a peak at $f_{\mathrm{o}}$, to unexplained variance in a band centered at $f_{0}$.

Extensive examples of the application of the multitaper method to hydroclimatic data are presented by Mann and Park (1993; 1994; 1996), Diaz and Pulwarty (1994), and Lall and Mann (1995). Lall and Mann (1995) also compare this method with another recently popular method for spectral analysis, called singular spectral analysis (Vautard et al., 1992) that may be better at identifying time patterns in the data, but worse for frequency domain analysis. Significance tests for testing for peaks (line components) in the spectrum associated with harmonics, are discussed by Mann and Lees (1996) and Thomson (1990). Thomson advocates nonparametric significance tests based on a jacknife or resampling approach. Mann and Lees (1996) consider more traditional alternatives, including the method by Thomson (1982) method, that are based on an assumption that the amplitudes $A_{j}$ and $B_{j}$ are Gaussian random variables and hence, the spectral ordinate or variance at a frequency $f_{j}$ has the $F$ distribution, with the dof dependent on the effective number of parameters and sample size subsequent to tapering or smoothing. They recommend two strategies: (1) testing against a null hypothesis of 'red noise' (AR1 process fitted to the data); and (2) a more flexible null hypothesis that assumes a 'locally white noise' background spectrum, whose variance is estimated as the median of the $S(f)$ values in a window $f_{j} \pm w_{f}$. The significance test is then based on a test statistic formed as the ratio of the $S\left(f_{j}\right)$ at frequency $f_{j}$, to the background value of $S(f)$ at $f_{j}$ estimated for either the 'red noise' (Eq. (2)) or the 'locally white noise' assumed backgrounds. Based on our experiments with synthetic data, we adopted the 'locally white noise' background approach to significance testing for peaks with $w_{f}=0.25$ cycles per year. This provided the most robust selection of frequencies for data that contained periodic components, trends and AR(1) components.

Our interest was in identifying quasi-periodic components in the precipitation series and relating them to some key climate indices, that were identified earlier. Since our model for both the site precipitation and the index series considers that the series have periodic as well as autoregressive, trend and 'noise' components, we may expect that even if both series have components of the same dynamical system that are periodic, the correlation across the raw series may not be very high. However, if we can identify the periodic components in each of the series first, it is meaningful to directly identify the correlation or coherence of these components or signals. Ultimately, if our interest lies in the prediction of precipitation using climate 
indices, this may provide us with a measure and means of predictability, component by component. The multi-taper estimate of spectral coherence $C(f)$ across two time series $x_{t}^{(1)}, t=0, \ldots, \mathrm{N}-1$, and $x_{t}^{(2)}$, $t=0, \ldots, N-1$, is estimated using Eq. (10). A confidence test (see Brillinger (1981)) similar to the $F$ variance ratio test is used to test for the significance of the coherence amplitude.

$$
C(f)=\frac{\sum_{k=0}^{K-1} y_{k}^{(1) *}(f) y_{k}^{(2)}(f)}{\left(\sum_{k=0}^{K-1} y_{k}^{(1) *}(f) y_{k}^{(1)}(f) \sum_{k=0}^{K-1} y_{k}^{(2) *}(f) y_{k}^{(2)}(f)\right)^{1 / 2}},
$$

where $(*)$ represents a complex conjugate.

Each of the time series given in Table 1 was analyzed using the multi-taper method to identify significant frequency peaks. Next, the spectral coherence between the precipitation series and the atmospheric indices (SOI and CNP) was estimated to identify the significant coherent frequencies. Finally, each time series was bandpassed at a few significant frequencies to see the nature of the underlying time variations associated with the quasi-periodic modes represented. The bandpass retains only the components of the time series that can be represented by harmonic components with frequencies in the specified band.

\section{Results from spectral analysis}

The results from the spectral analysis of individual series are summarized in Table 2. The sites are arranged from north to south (downwards). The periods reported correspond to peaks that are higher than the $90 \%$ significance level based on the 'locally white noise' assumption null hypothesis. Examples of spectra and confidence limits for the precipitation and rate time series for Priest River, ID; Logan, UT; Tucson, AZ; SOI and CNP, are shown in Fig. 1(a)-(h).

After a preliminary screening of the spectral output, it was clear that one could designate bands in which there was statistically significant power. These bands were generally consistent with the frequency bands in which hydroclimatic data show evidence of activity (Lall and Mann, 1995; Mann et al., 1995; Mann and Park, 1996). In selecting these bands, we also considered the width of the frequency window ( 0.033 cycles per year for the 61 years of data) associated with a spectral estimate at a given frequency. The resulting frequency bands were designated as 2$3,3-6,6-9$ and 10 years longer. While several spectra had peaks in a interdecadal band centered around 15 years, we chose to lump these with the secular band (trend) given the relatively short length of the records analyzed. The activity in the $2-3$ year band is

Table 2

Results from spectral analysis

\begin{tabular}{|c|c|c|c|c|}
\hline Data set & $\begin{array}{l}\text { Period (years) } \\
2-3\end{array}$ & $3-6$ & $6-9$ & \rangle 10 \\
\hline PRR-R & & 4.7 & & $\mathrm{x}$ \\
\hline PRR-P & & 4.3 & 8.3 & $\mathrm{x}$ \\
\hline SNP-R & 2.4 & & 8.5 & $\mathrm{x}$ \\
\hline SNP-P & & 4.5 & 8.5 & \\
\hline LOG-R & 2.1 & & & $\mathrm{x}$ \\
\hline LOG-P & 2.1 & & & $\mathrm{x}$ \\
\hline SNC-R & 2.1 & & 7.7 & $\mathrm{x}$ \\
\hline SNC-P & 2.1 & & 6.3 & $\mathrm{x}$ \\
\hline ALT-R & 2.6 & & & $\mathrm{x}$ \\
\hline \multicolumn{5}{|l|}{ ALT-P } \\
\hline MIM-R & & & & $\mathrm{x}$ \\
\hline MIM-P & 2.7 & & 6.3 & \\
\hline TUS-R & 2.6 & & 6.3 & \\
\hline TUS-P & 2.8 & 5.3 & & $\mathrm{x}$ \\
\hline SOI & 2.5 & 4.3 & & \\
\hline CNP & & 3.3 & & $\mathrm{x}$ \\
\hline
\end{tabular}

$\mathrm{R}$ refers to the rate of occurrence and $\mathrm{P}$ to the precipitation amount. The significance was checked at the $90 \%$ level. 
1(a) PRR-P

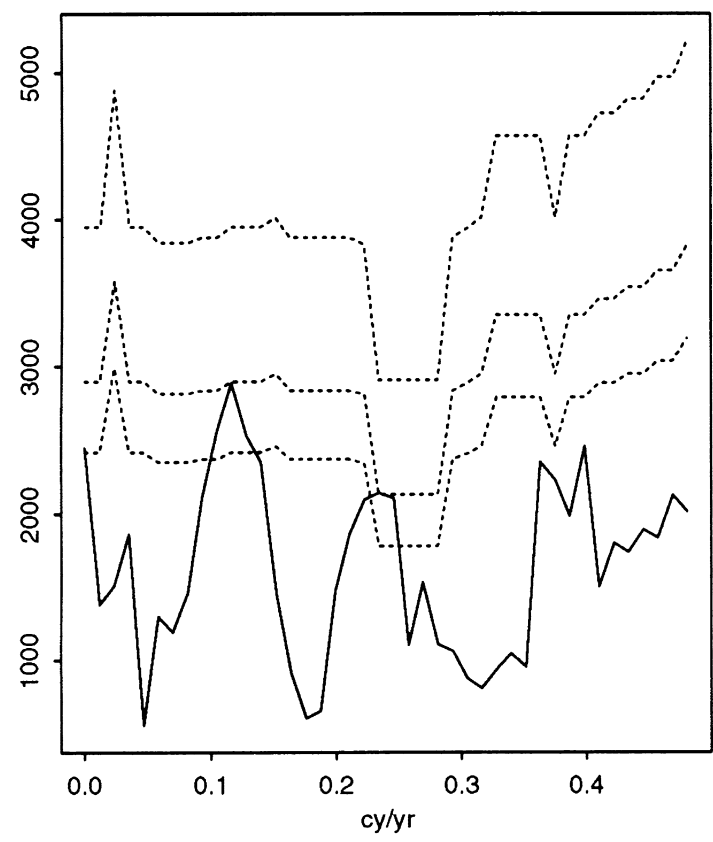

1(c) TUS-P

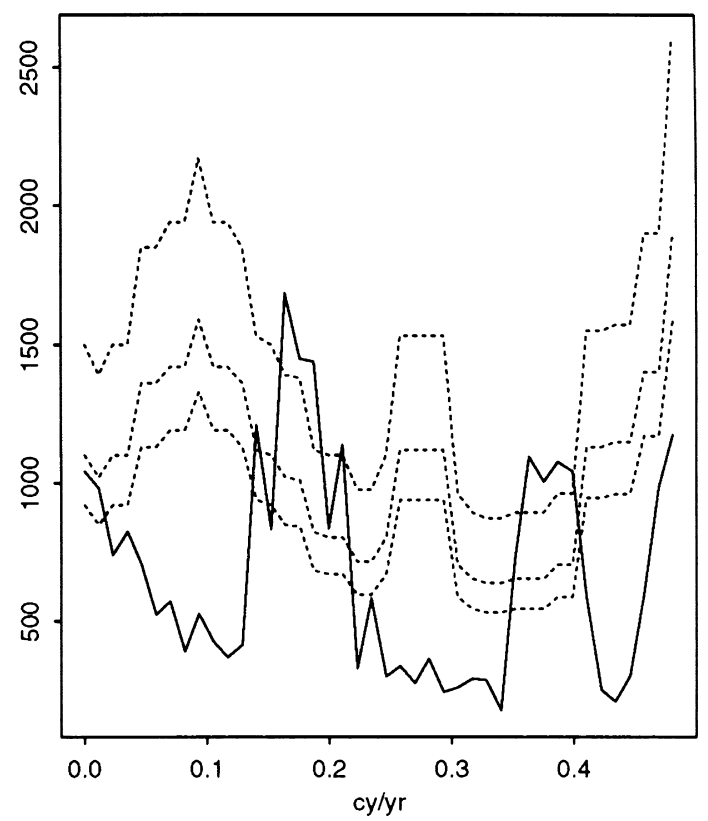

1(b) LOG-P

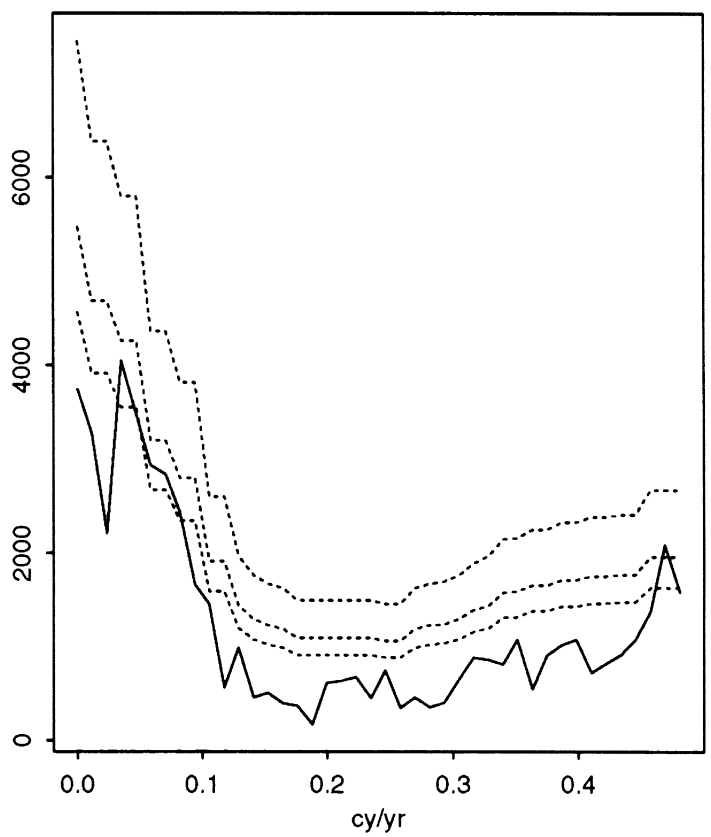

1(d) PRR-R

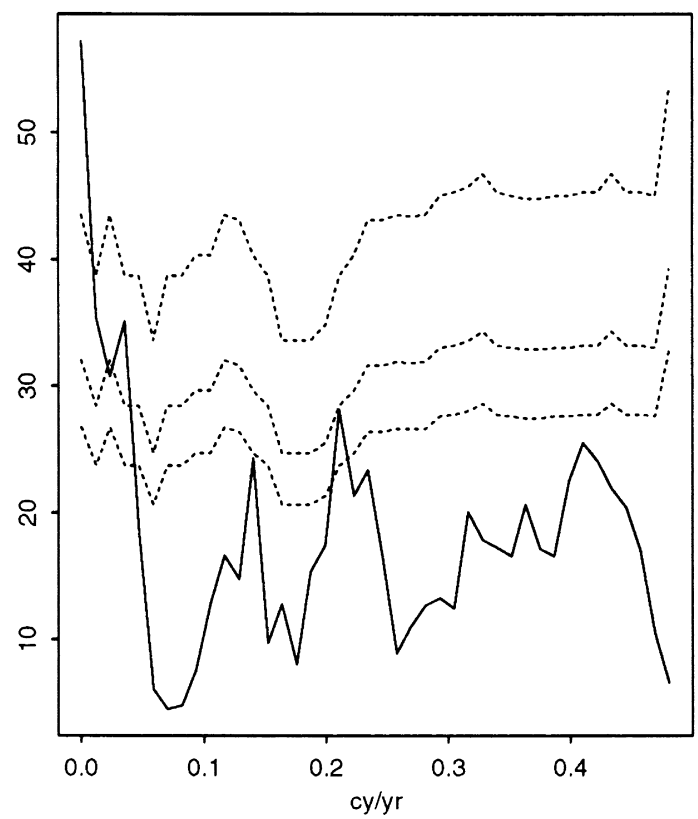

Fig. 1. Spectra of precipitation amount from data at: (a) Priest River, ID; (b) Logan, UT; and (c) Tuscon, AZ. Spectra of precipitation occurrence rate from data at: (d) Priest River, ID; (e) Logan, UT; and (f) Tuscon, AZ. Spectra of: (g) SOI; and (h) CNP. In all these figures the dotted lines represent the $90 \%, 95 \%$ and $99 \%$ confidence levels. 
1(e) LOG-R

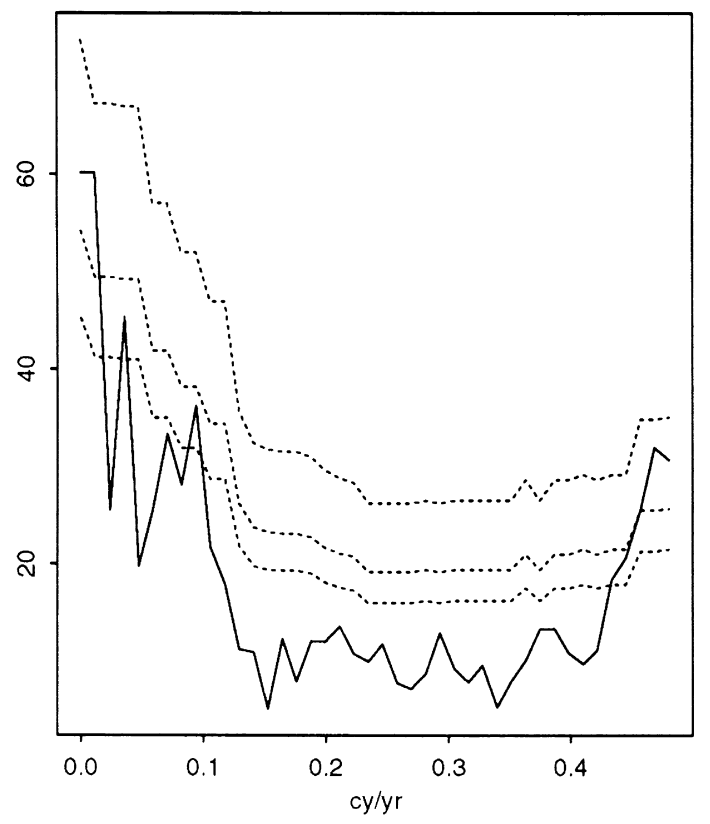

1 (g) SOI

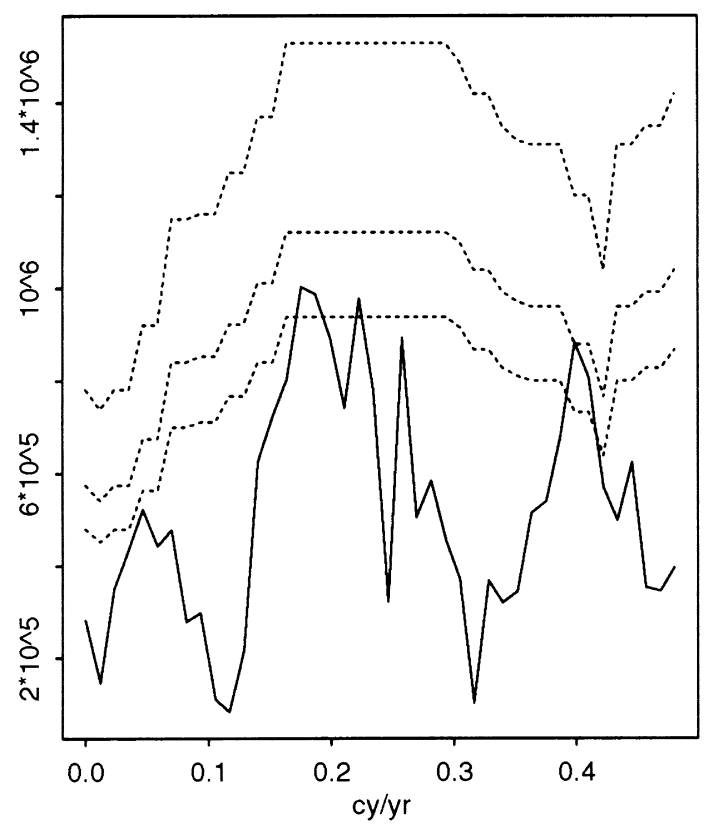

1(f) TUS-R

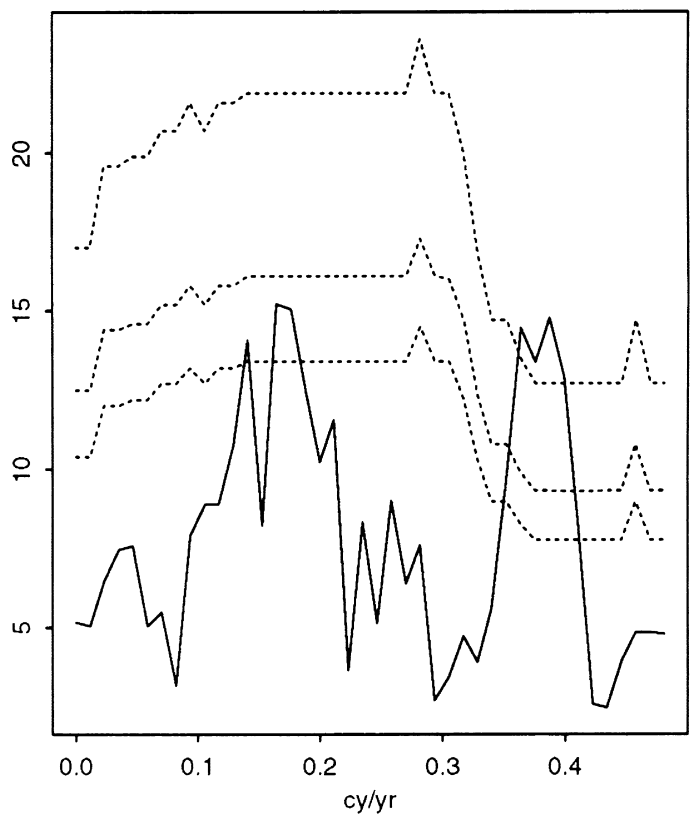

1(h) CNP

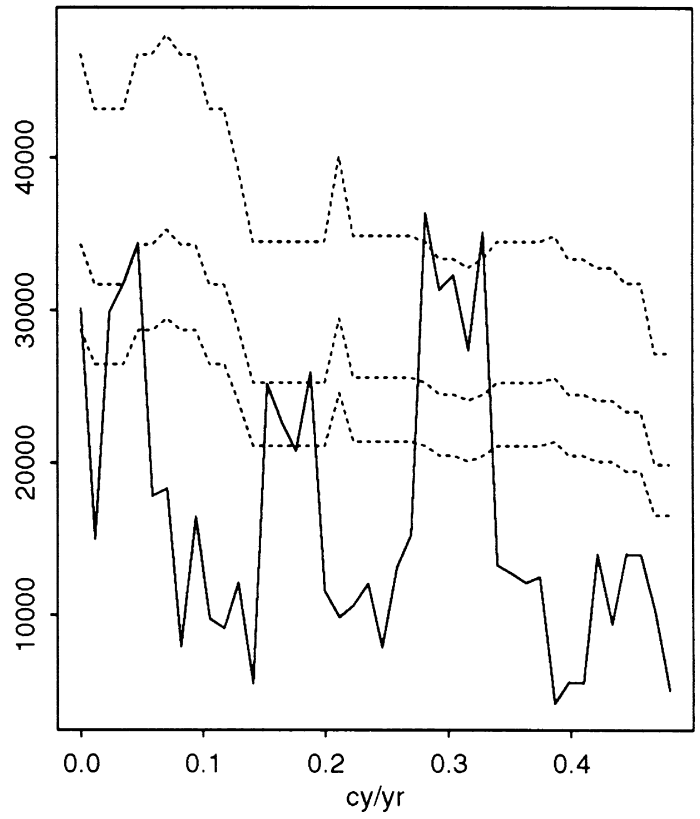

Fig. 1. (continued) 
usually associated with the Quasi-Biennial Oscillation (Trenberth and Shin, 1984) and the high-frequency end of ENSO. Variability at this time scale has been observed in north-south US temperatures by Dettinger and Ghil (1991), in winds and sea level pressures by Deser and Blackmon (1993), and in air temperatures by Gordon et al. (1992). The 3-6 year band is usually associated with ENSO, and the 6-9 year band is presumed to reflect the nonlinear interaction between QBO and ENSO (Labitzke and Van Loon, 1988; Barnston et al., 1991). The ( $>10$ years) band may reflect the decadal scale variability of the Northern Pacific activity, due to interaction between ENSO and feedback effects in the extratropics (Kumar et al.,

2(a) - PRR

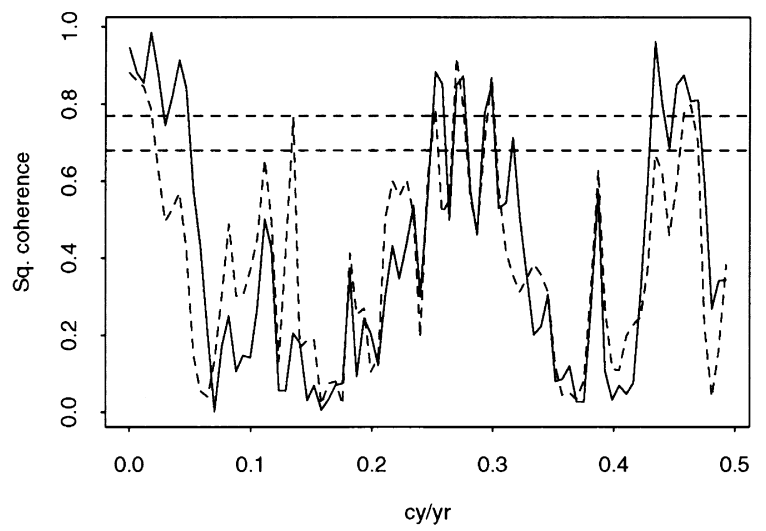

2(c) - TUS

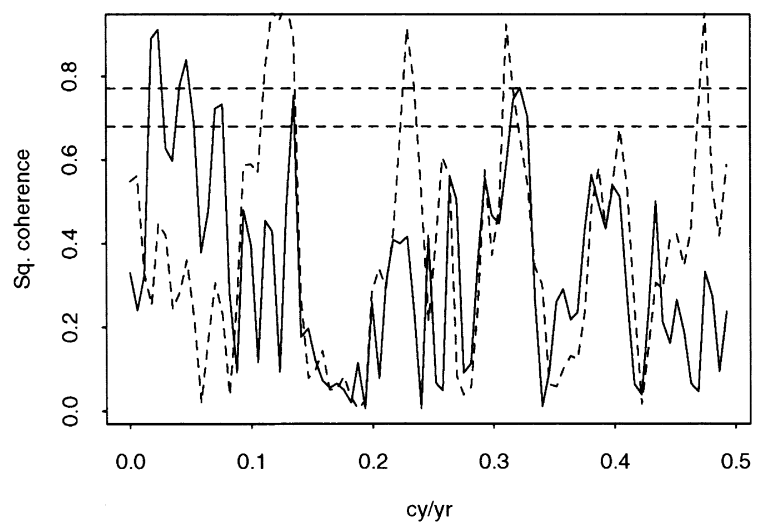

1994; Trenberth and Hurrell, 1994), and also the century-long warming trend (Cane et al., 1997). This band is prominent in the analysis of most series. While the period associated with individual significant peaks varies, once one recognizes that the analysis can only identify frequencies within a band of \pm 0.033 cycles per year, it is seen that the peaks cluster around 2, 3, 4, 5 and 8 years.

Representative multi-taper method estimates of coherence of the precipitation amount and rate time series at Priest River, Logan, Tucson, and SOI with CNP, are presented in Fig. 2(a)-(d). The dashed horizontal lines in these figures show the $90 \%$ and $95 \%$ confidence levels for squared coherence. Table 3

$$
\text { 2(b) - LOG }
$$

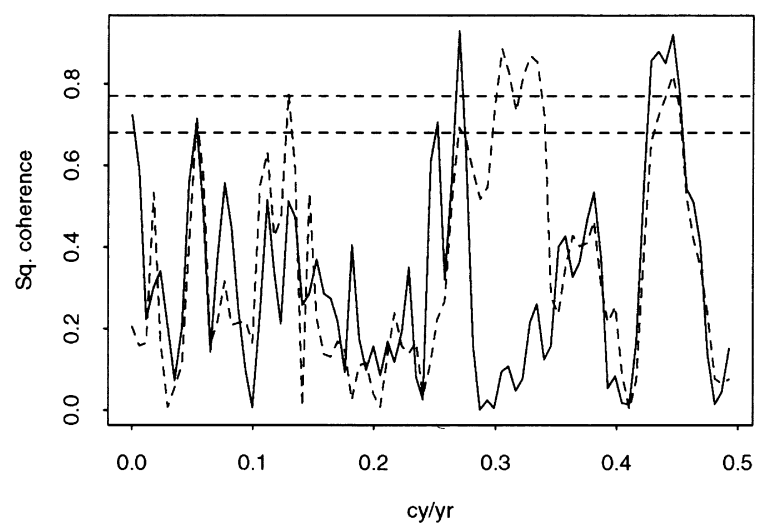

2(d) - SOI/CNP

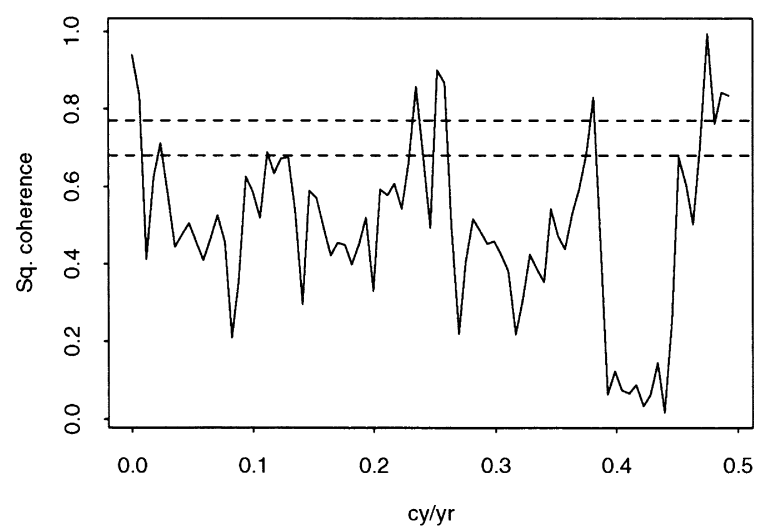

Fig. 2. Spectral coherence between CNP and precipitation amount (solid line); between CNP and precipitation occurrence rate (dashed line) from data at: (a) Priest River, ID; (b) Logan, UT; and (c) Tuscon, AZ. Spectral coherence: (d) between SOI and CNP. The dashed horizontal lines in all these figures indicate the $90 \%$ and $95 \%$ confidence levels. 
Table 3

Results from coherence analysis

\begin{tabular}{|c|c|c|c|c|}
\hline Data set & $\begin{array}{l}\text { Period } \\
2-3\end{array}$ & $3-6$ & $6-9$ & \rangle 10 \\
\hline \multicolumn{5}{|c|}{ Coherence with CNP } \\
\hline PRR-R & 2.2 & 3.7 & 7.4 & \\
\hline PRR-P & 2.5 & 3.5 & & $\mathrm{x}$ \\
\hline SNP-R & 2.6 & $3.5,5.7$ & 6.8 & $\mathrm{x}$ \\
\hline SNP-P & 2.5 & 4 & & \\
\hline LOG-R & 2.2 & 3.2 & 7.8 & $\mathrm{x}$ \\
\hline LOG-P & 2.2 & 3.7 & & $\mathrm{x}$ \\
\hline SNA-R & 2.2 & 3.3 & 7.8 & $\mathrm{x}$ \\
\hline SNA-P & $2.2,2.8$ & $3.7,5.7$ & $6.9,9$ & $\mathrm{x}$ \\
\hline ALT-R & 2.7 & 3.7 & & $\mathrm{x}$ \\
\hline ALT-P & 2.7 & $3.5,4.3$ & & \\
\hline MIA-R & 2.2 & $3.2,4.5$ & & $\mathrm{x}$ \\
\hline MIA-P & & 3.2 & 7.4 & $\mathrm{x}$ \\
\hline TUS-R & 2.1 & $3.2,4.3$ & $7.4,8.5$ & $\mathrm{x}$ \\
\hline TUS-P & & 3.1 & 7.4 & $\mathrm{x}$ \\
\hline \multicolumn{5}{|c|}{ Coherence with SOI } \\
\hline PRR-R & & 3.7 & & \\
\hline PRR-P & & & & $\mathrm{x}$ \\
\hline SNP-R & & & & $\mathrm{x}$ \\
\hline SNP-P & & 3.4 & & \\
\hline LOG-R & 2.5 & 3.6 & 7.8 & $\mathrm{x}$ \\
\hline LOG-P & 2.6 & & 7.4 & \\
\hline SNA-R & & & 7.8 & $\mathrm{x}$ \\
\hline SNA-P & 2.5 & $3.2,4.3$ & 9 & \\
\hline ALT-R & & 5 & 8.5 & \\
\hline ALT-P & 2.5 & 4.7 & & $\mathrm{x}$ \\
\hline MIA-R & 2.1 & 3.7 & 9 & $\mathrm{x}$ \\
\hline MIA-P & & 4.7 & 7.4 & $\mathrm{x}$ \\
\hline TUS-R & 2.5 & 3.8 & & $\mathrm{x}$ \\
\hline TUS-P & 3 & & 7.4 & $\mathrm{x}$ \\
\hline CNP & & & 4.3 & $\mathrm{x}$ \\
\hline
\end{tabular}

$\mathrm{R}$ refers to the rate of occurrence and P refers to the precipitation. For 3, $2 \pi$ tapers the F value for the squared coherence at $90 \%$ confidence is 0.68 .

presents the frequencies with statistically significant coherence between the precipitation time series, and SOI and CNP. The frequencies at which the coherence between two series is significant, corresponds to a significant or near-significant peak in the spectra of one or both of the series. In general, the occurrence rate exhibits a stronger coherence than the precipitation amount with the atmospheric indices. The occurrence rate may hence, be a better indicator of the atmospheric variability-precipitation connection. This could be: (1) because of nonlinearity in the generation of precipitation as a function of atmospheric flow; and (2) because precipitation occurrence may have a larger coherent spatial 'signal' than the precipitation amount, which may fluctuate quite a bit due to local influences. Also, note that the patterns that emerge in spectral coherence with SOI are more similar as we move southwards. Likewise, the patterns of spectral coherence with CNP are more similar as we move northwards. This is consistent with the observations of Cayan and Peterson (1989), Cayan and Webb (1992), Kahya and Dracup (1994) and others in western US, using streamflow data, and precipitation and temperature data (Ropelewski and Halpert, 1986; Yarnal and Diaz, 1986).

Noting that a number of significant frequencies 
from the multi-taper method spectra (Table 2) and from coherence analysis (Table 3) are in the 36 year period, we bandpassed each of the time series to retain only this frequency band. Bandpassing can be thought of as filtering using the desired frequency band, or constructing a moving average of the data such that contributions from averaging periods outside the bandpass (3-6 years here) are excluded. The amplitude of the bandpassed series of SOI and CNP vary similarly over time, as can be seen from Fig. 3(a). Consequently, representative bandpassed series of precipitation amount and CNP, Fig. 3(b)(d), and rate and CNP, Fig. 3(e)-(g), at the three stations, are presented. Note that for Priest River, Fig. 3(b) and (e), the amplitudes of precipitation amount and rate are in phase with CNP. Logan, Fig. 3(c) and (f), also exhibits similar behavior. As we move to Tucson, Fig. 3(d) and (g), there appears to be a considerable phase shift. For the stations in between Tucson and Priest River, transitional behavior was observed.

The coherence between the bandpassed series of CNP and the precipitation amount at the southernmost station (Tucson) is 0.7 ; for the station in the middle (Logan) of the transect it is 0.78 ; while it is 0.84 for the northern-most station (Priest River), respectively. The coherence with SOI was $0.81,0.6$ and 0.5, respectively at Tucson, Logan and Priest River. The $90 \%$ significance level for coherence is 0.78 , suggesting that SOI is important primarily for the Southern stations in this frequency band. The phase lag of the precipitation amount with CNP increases, the coherence decreases moving south, and with SOI the coherence increases moving south. This observation is consistent with our expectation, since CNP is a more direct measure of the atmospheric flow (jet stream behavior) in the northern end of the domain, while the SOI may more directly measure the modulation of the atmospheric flow in the lower latitudes, through tropical variability. Of course, the SOI and CNP may reflect related modes of atmosphere-ocean variability as well.

Finally, the spatial tendencies of the significant spectral peaks in occurrence rate and precipitation amount, and their coherence with CNP and SOI, are presented in Figs. 4 and 5. There is an indication that the lower frequency bands in the spectrum are preferred by the precipitation series in the northern part of the region, but this is not a pronounced trend. No major spatial trends with respect to the coherence of the precipitation series with CNP are readily apparent, i.e. the signature is present essentially across the region. However, the precipitation series in the southern part of the region appear to be more strongly correlated with the SOI. As noted earlier, the rate series are more often coherent with the atmospheric indices.

\section{Conclusion}

Spectral analysis was performed on time series of precipitation amount and rates at seven stations along a meridional transect from Arizona to Idaho. We find consistent evidence for structured low-frequency variability from the spectral analysis. Strong signals in the 3-7 and 2-3 year periods were revealed from the analysis, which seem to be consistent across time series. These interannual signals are consistent with El Niño southern oscillation (ENSO) and quasi-biennial variability identified by others. Spectral coherence between the precipitation amounts and rates with CNP and SOI were also shown to be significant in the above frequency range.

The high coherence between precipitation amount and rates with SOI and CNP, and also the significant frequencies in the ENSO band as suggested by the analyses here, has directed our efforts into seeking an understanding of the coherent spatial variability of these variables at the chosen locations.

A number of authors (Ropelewski and Halpert, 1986 Ropelewski and Halpert, 1987; 1989; Cayan and Peterson, 1989; Cayan and Webb, 1992; Kahya and Dracup, 1994) have looked for connections between El Niño and La Niña events and precipitation, temperature and streamflow series in the western US, by focusing on first identifying El Niño/La Niña years in the record, and then looking for evidence of anomalous behavior in the at site hydrological variables over a time window, centered at each such year. Such an approach is attractive, because it is easily understood and communicated. One can even visually present the results of such an analysis to show spatial patterns quite effectively (e.g. Kahya and Dracup, 1993). Such an analysis is justified for episodic climate variability, which is one paradigm for ENSO. 


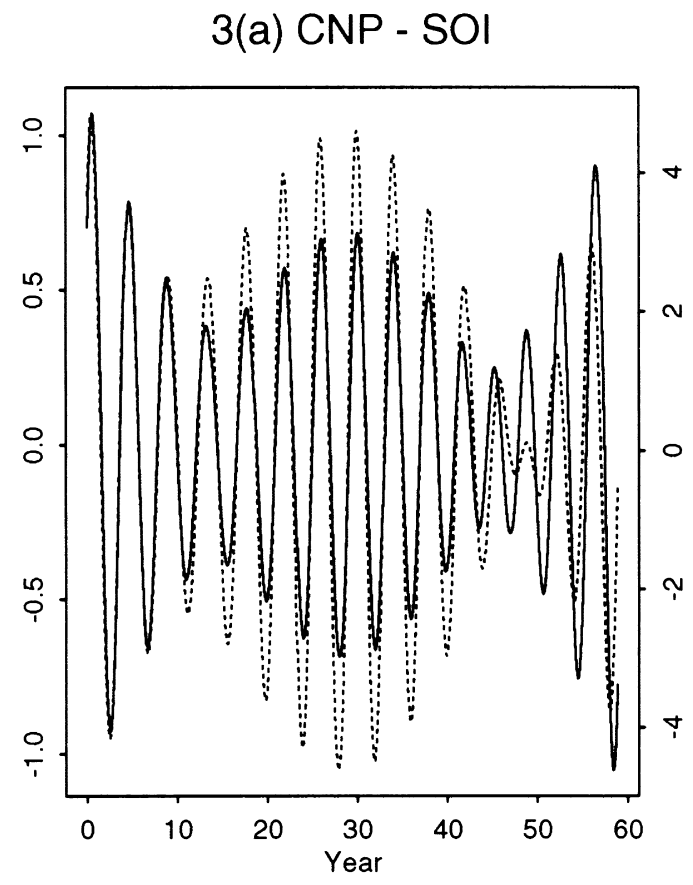

3(c) CNP - LOG-P

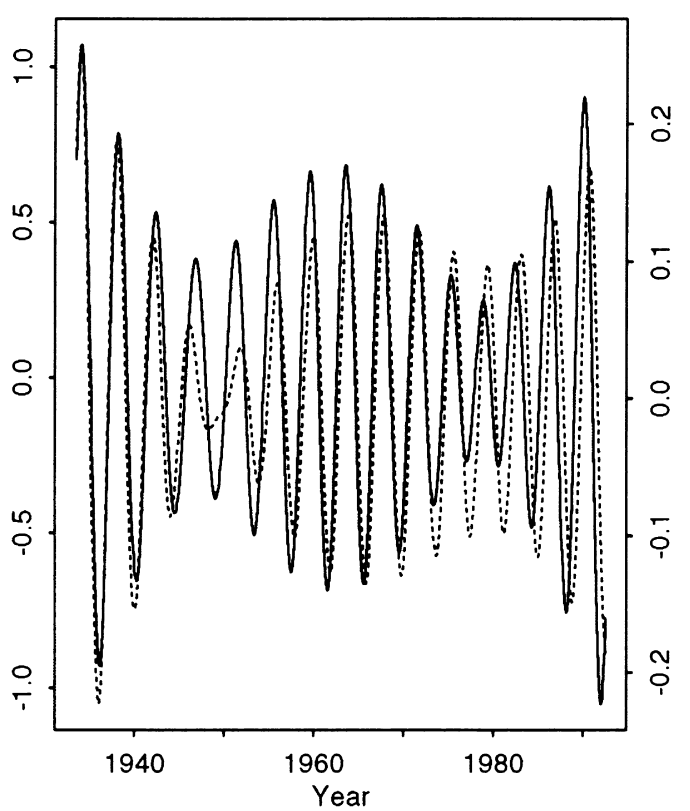

3(b) CNP - PRR-P

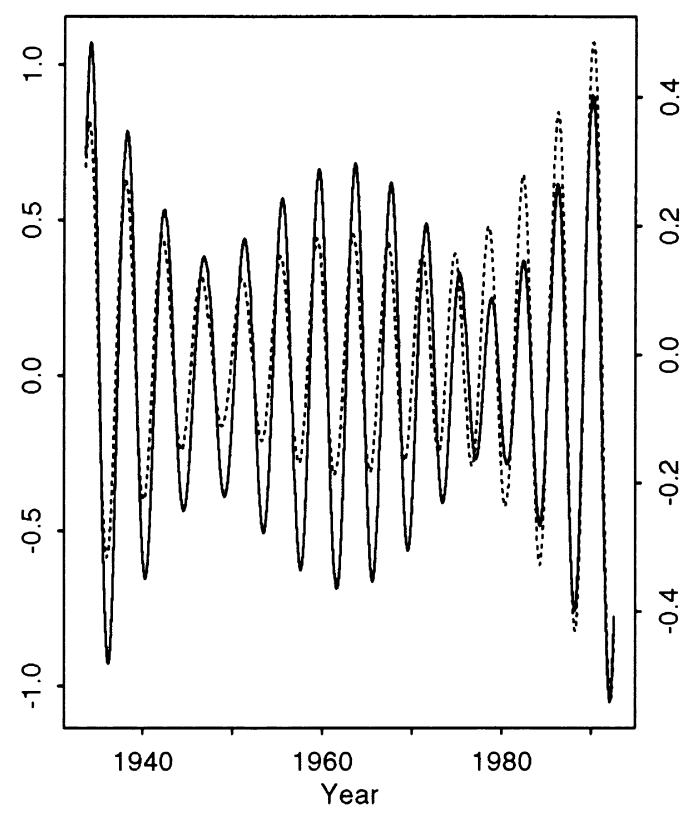

3(d) CNP - TUS-P

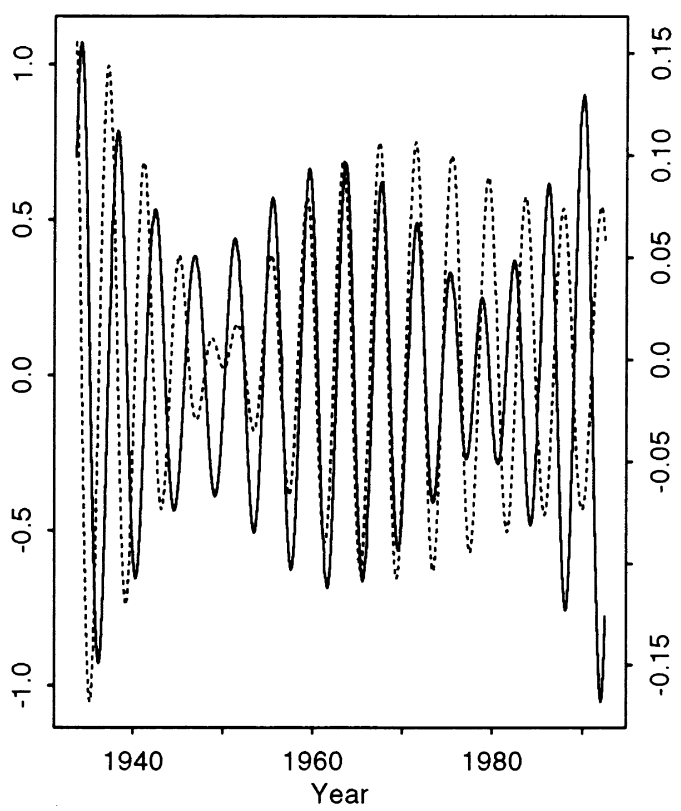

Fig. 3. Bandpassed series of CNP (solid line) and: (a) SOI (dotted line); precipitation amount (dotted line) from data at (b) Priest River, ID; (c) Logan, UT; (d) Tuscon, AZ; and precipitation occurrence rate (dotted line) from data at: (e) Priest River, ID; (f) Logan, UT; and (g) Tuscon, $\mathrm{AZ}$ (the solid line in all these figures is the bandpassed series of CNP). 

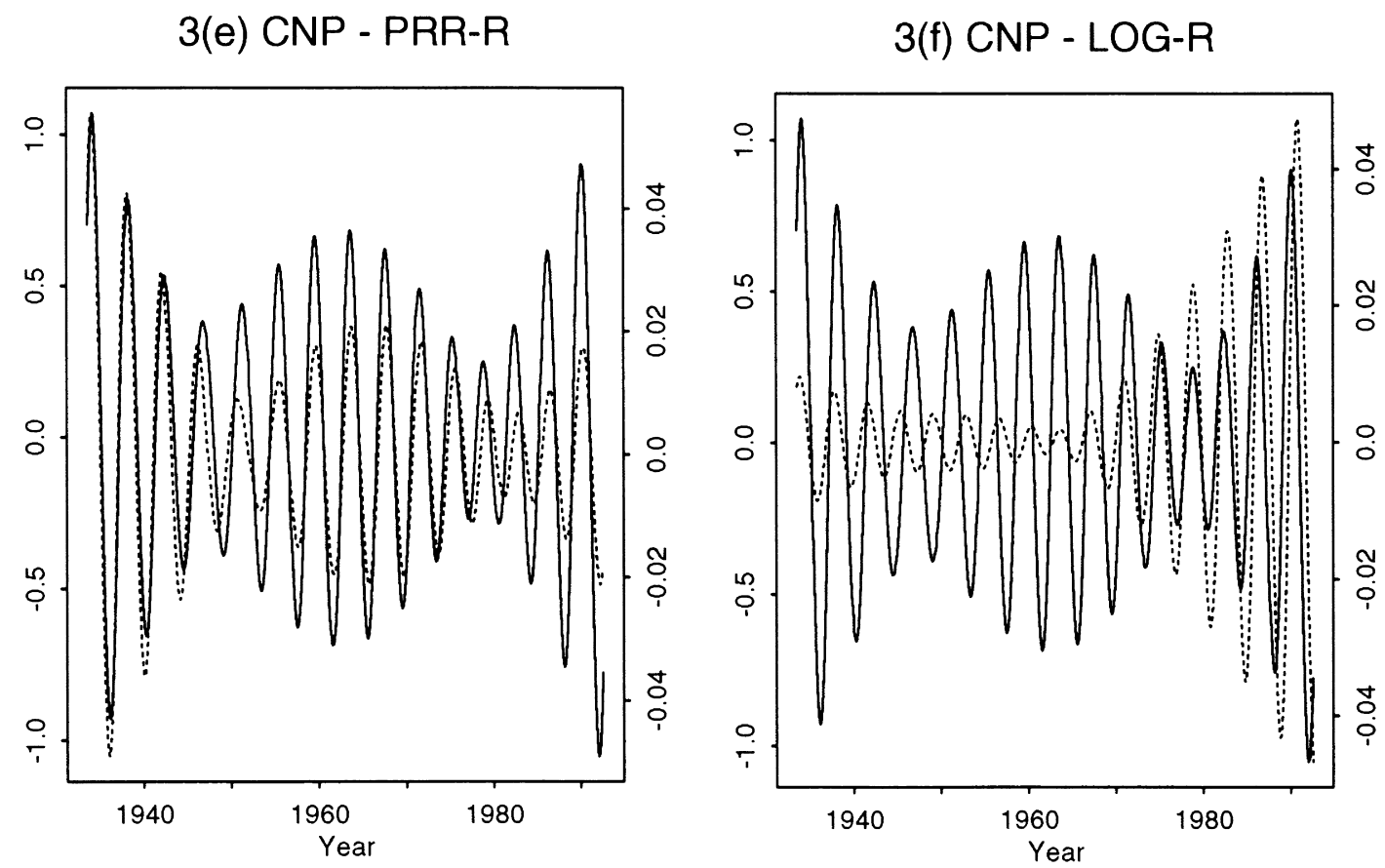

3(g) CNP - TUS-R

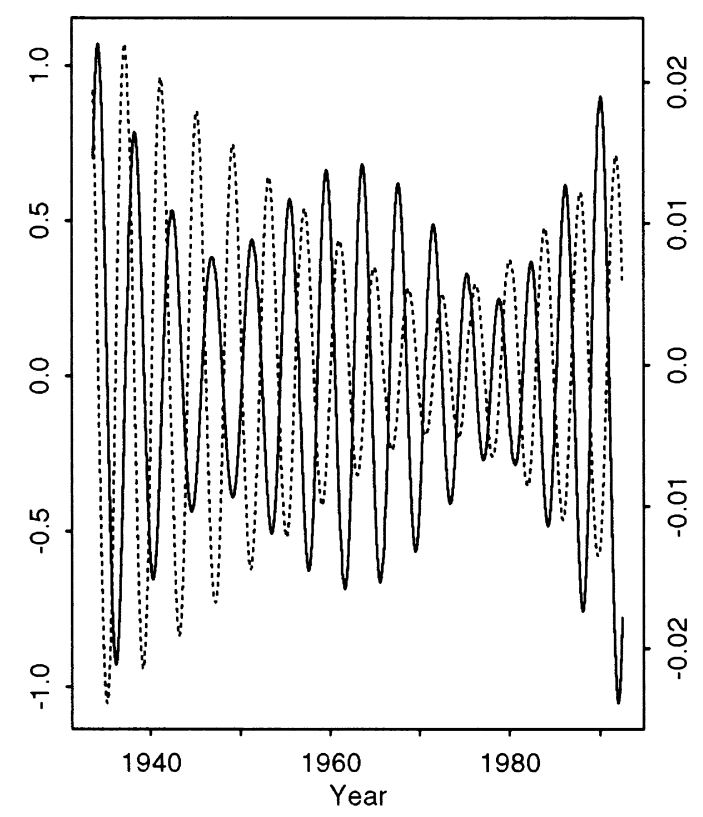

Fig. 3. (continued). 
Significant Peaks
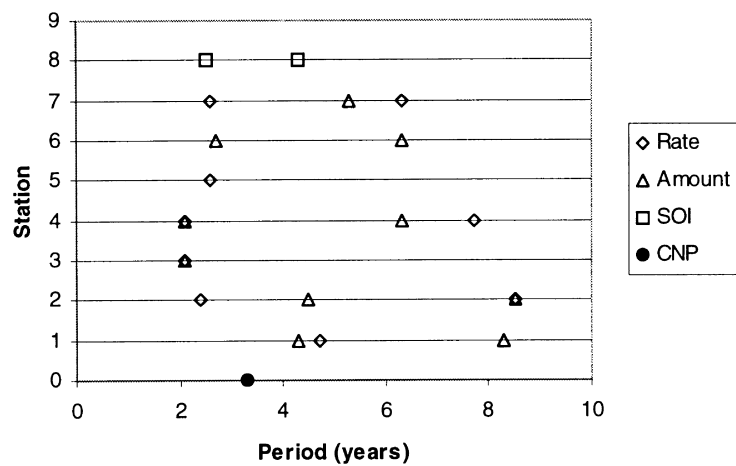

Fig. 4. Significant spectral peaks for each of the series analyzed. Station 0 corresponds to CNP, station 8 to SOI, and stations 1-7 are: PRR, SNP, LOG, SNA, ALT, MIA and TUS.

\section{Coherence With CNP}

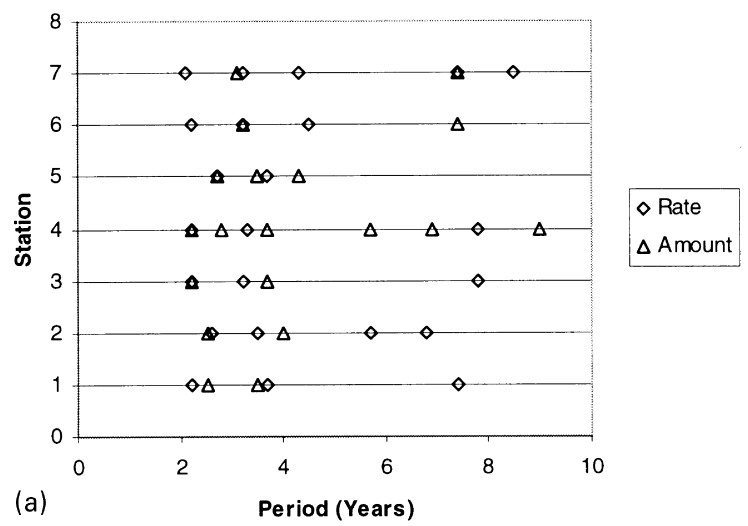

Coherence With SOI

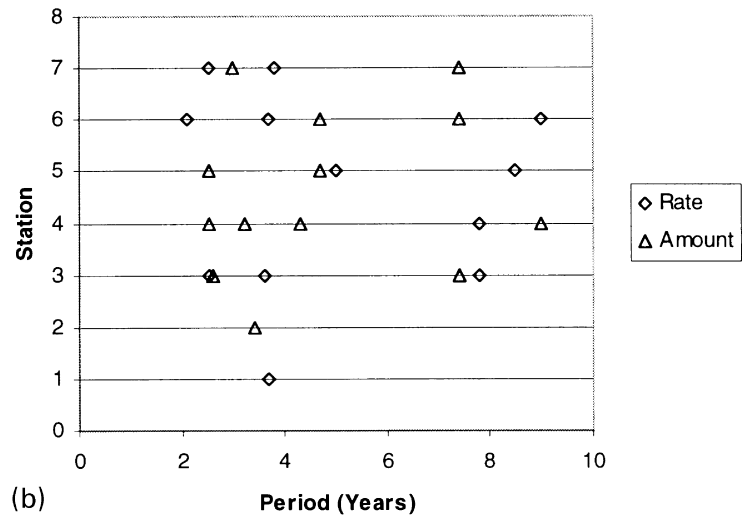

Fig. 5. Coherence of each precipitation series with: (a) CNP; and (b) SOI. Stations 1-7 are: PRR, SNP, LOG, SNA, ALT, MIA and TUS. 
The multi-taper method-based approach presented here, allows one to go beyond such analyses - one can identify frequency bands where there is structure in individual series, check to see if such structure is coherent across the series analyzed and directly assess the associated phase lags, and finally bandpass the series at selected frequency bands to examine connections between the different time series. The most striking example of the utility of such an analysis is the suggestion of a meridional (south to north) pattern in the interaction of tropical atmospheric variability (as represented by ENSO) with continental precipitation. It is also interesting that the connections seem to manifest themselves more clearly through a North Pacific index of atmospheric circulation than the SOI directly. Is this simply because the CNP index is defined at a geographically closer location? Or, is there a suggestion that the high latitude North Pacific atmospheric flow is more directly modulated by the tropical variability? The latter is an area of active research.

Finally, it is worth noting that the ENSO phenomena itself is nonstationary (Mann and Park, 1996; Rajagopalan et al., 1997). The relative variance in the 3-6 and 6-9 year frequency bands, varies over the record. The lower frequency band (6-9 years) is more important in the 1940-1970 period, when there were relatively few El Niño events, while the higher frequency band (3-6 years) is more prominent in the earlier and later period, when ENSO events have been more frequent. Given, the limited length of the precipitation records used here, we chose to perform the analysis using a single fixed period equal to the length of the record, rather than doing a moving window analysis to highlight the time varying nature of the climatic oscillations. Wavelet or moving window spectral analyses may be better descriptors of such transitory oscillatory phenomena. However, statistical significance testing is not yet well established for these methods, and for planning purposes it may be adequate to recognize the 'average' frequency of occurrence of these periodic phenomena.

\section{Acknowledgements}

Partial support of this work by the US Forest Service under contract no. INT-92660-RJVA, amendment no. 1 , is acknowledged. The principal investigator for this project was D.S. Bowles. Mike Mann's help in providing and installing the multitaper method routines is thankfully acknowledged. We thank the three anonymous reviewers and Dr David Maidment, for comments that helped improve the content and style of the manuscript.

\section{References}

Barnston, A.G., Livezey, R.E., Halpert, M.S., 1991. Modulation of southern oscillation-northern hemisphere mid-winter climate relationships by the QBO, J. Climatol., 4, 203-227.

Bartlett, M.S., 1966. An introduction to stochastic processes. Cambridge University Press, Cambridge, UK, p. 362.

Bradley, R.S., Diaz, H.F., Kiladis, G.N., Eischeid, J.K., 1987. ENSO signal in continental temperature and precipitation records, Nature, 327 (11), 497-501.

Brillinger, D.R., 1981. Time Series, Data Analysis and Theory. Holden-Day, San Francisco.

Burroughs, W.J., 1992. Weather Cycles: Real or Imaginary? Cambridge University Press.

Cane, M.A., 1986. El Niño , Ann. Rev. Earth Planet. Sci., 14, 4370.

Cane, M.A., Clement, A.C., Kaplan, A., Kushnir, Y., Pozdnyakov, D., Seager, R., Zebiak, S.E., Murtugudde, R., 1997. Twentiethcentury sea surface temperature trends, Science, 275, 957960.

Cayan, D.R., Peterson, D.H., 1989. The influence of north Pacific atmospheric circulation on streamflow in the west. Aspects of climate variability in the Pacific and the Western Americas, Amer. Geophys. Union, Geophys. Monogr., 55, 75-397.

Cayan, D., Webb R., 1992. El Niño/southern oscillation and streamflow in the western United States. In: Diaz, H.F., Markgraf, V. (Eds.), El Niño: Historical and Paleoclimatic Aspects of the Southern Oscillation. Cambridge University Press, pp. 29-68.

Deser, C., Blackmon, M., 1993. Surface climate variations over the North Atlantic ocean during winter: 1900-1989, J. Climatol., 6, 1743-1753.

Dettinger, M. D., Ghil, M., 1991. Interannual and interdecadal variability of surface-air temperatures in the United States. In Proc. XVIth Annual Climate Diagnostics Workshop, U.S. Department of Commerce, NOAA, Los Angeles, CA, pp. 209-214.

Diaz, H.F., Pulwarty, R.S., 1994. An analysis of the time scales of variability in centuries-long ENSO-sensitive records in the last 1000 years, Climatic Change, 26 (2) 3, 317-342.

Gordon, A.L., Zebiak, S.E., Bryan, K., 1992. Climate variability and the Atlantic Ocean, Eos Trans., AGU, 73, 161-165.

Horel, J.D., Wallace, J.M., 1981. Planetary-scale atmospheric phenomena associated with the Southern Oscillation, Mon. Weather Rev., 109, 813-829.

Jenkins, G.M. and Watts, D.G., 1968. Spectral Analysis and its applications. Holden-Day, San Francisco. 
Kahya, E., Dracup, J.A., 1993. U.S. Streamflow patterns in relation to the El-Niño/Southern Oscillation, Water Resour. Res., 29 (8), 2491-2503.

Kahya, E., Dracup, J.A., 1994. The influences of type 1 El Niño and La Niña events on streamflows in the south-western U.S., J. Climatol., 7 (6), 965-976.

Kiladis, G.N., Diaz, H.F., 1989. Global climatic anomalies associated with extremes in the Southern Oscillation, J. Climatol., 2, 1069-1090.

Klein, W.H., Bloom, H.J., 1987. Specification of monthly precipitation over the United States from the surrounding $700 \mathrm{mb}$ height field, Mon. Weather Rev., 115, 2118-2132.

Kumar, A., Leetma, A., Ji, M., 1994. Simulations of atmospheric variability induced by sea surface temperatures and implications for global warming, Science, 266, 632-634.

Labitzke, K., Van Loon, H., 1988. Associations between the 11year solar cycle, the QBO, and the atmosphere, I. The troposphere and stratosphere in the northern hemisphere in winter, J. Atmos. Terr. Phys., 50, 197-206.

Lall, U., Mann, M., 1995. The Great Salt Lake: a barometer of low frequency climatic variability, Water Resour. Res., 31, 25032515.

Leathers, D.J., Yarnal, B., Palecki, M., 1991. The Pacific/North American teleconnection pattern and United States climate. Part I: regional temperature and precipitation associations, J. Climatol. Appl. Meteorol., 24, 463-471.

Lins, H.F., 1993. Streamflow variability in the United States: 1931-1979, J. Climatol. Appl. Meteorol., 29, 463-471.

Mann, M.E., Lees, J., 1996. Robust estimation of background noise and signal detection in climatic time series, Clim. Change, 33 (3), 409-445.

Mann, M.E., Park, J., 1993. Spatial correlations of interdecadal variation in global surface temperatures, Geophys. Res. Lett., 20, 1055-1058.

Mann, M.E., Park, J., 1994. Global modes of surface temperature variability on interannual to century time scales, J. Geophys. Res., 99 (D12), 25819-25833.

Mann, M., Park, J., 1996. Joint spatio-temporal modes of surface temperature and sea level pressure variability in the northern hemisphere during the last century, J. Climatol., 9, 2137-2162.

Mann, M., Lall, U., Saltzman, B., 1995. Low frequency climate variability: understanding the rise and fall of the Great Salt Lake, Geophys. Res. Lett., 22, 937-940.

Peixoto, J.P., Oort, A.H., 1992. Physics of Climate, AIP, New York.
Percival, D.B., Walden, A.T., 1993. Spectral Analysis for Physical Applications - Multitaper and Conventional Univariate Techniques, Cambridge University Press, New York.

Philander, S.G., 1990. El Niño, La Niña and the Southern Oscillation, Academic, San Diego, CA.

Piechota, T.C., Dracup, J.A., 1994. Precipitation and temperature patterns in the United States associated with El Niño/Southern Oscillation, Water Resour. Res., 32 (5), 1359-1373.

Rajagopalan, B., Lall, U., Cane, M., 1997. Anomalous ENSO occurrences: an alternate view, J. Climatol., 10 (9), 2351-2357.

Rasmusson, E.M., Carpenter, T.H., 1983. The relationship between eastern equatorial Pacific sea surface temperatures and rainfall over India and Sri Lanka, Mon. Weather Rev., 111, 517-528.

Rasmusson, E.M., Wallace, J.M., 1993. Meteorological aspects of the El Niño/Southern Oscillation, Science, 222, 1195-1202.

Redmond, K.T., Koch, R.W., 1991. Surface climate and streamflow variability in the western United States and their relationship to large-scale circulation indices, Water Resour. Res., 27 (9), 2381-2399.

Ropelewski, C.F., Halpert, M.S., 1986. North American precipitation and temperature patterns associated with the El Niño/ Southern Oscillation (ENSO), Mon. Weather Rev., 114, 2352-2362.

Ropelewski, C.F., Halpert, M.S., 1987. Global and regional scale precipitation patterns associated with the El Niño/Southern Oscillation, Mon. Weather Rev., 115, 1606-1626.

Ropelewski, C.F., Halpert, M.S., 1989. Precipitation patterns associated with the high index phase of the Southern Oscillation, J. Climatol., 2, 268-284.

Thomson, D.J., 1982. Spectrum estimation and harmonic analysis, IEEE Proc., 70, 1055-1096.

Thomson, D.J., 1990. Quadratic-inverse spectrum estimates: applications to paleoclimatology, Phil. Trans. R. Soc. London, Ser. A, 332, 539-597.

Trenberth, K.E., Hurrell, J.W., 1994. Decadal atmosphere-ocean variations in the Pacific, Clim. Dyn., 9, 303-319.

Trenberth, K.E., Shin, W.T.K., 1984. Quasibiennial fluctuations in sea level pressures over the northern hemisphere, Mon. Weather Rev., 112, 761-777.

Vautard, R., Yiou, P., Ghil, M., 1992. Singular spectrum analysis: a toolkit for short, noisy and chaotic series, Physica D, 58, 95126.

Yarnal, B., Diaz, H.F., 1986. Relationships between extremes of the Southern Oscillation and the winter climate of the AngloAmerican Pacific Coast, J. Climatol., 6, 197-219. 